Sonntag, Hermann; Haueisen, Jens; Lau, Stephan ; Eichardt, Roland; Wolters,

Carsten H.; Vorwerk, Johannes; Grasedyck, Lars; Güllmar, Daniel:

Influence of finite element discretization on the EEG/MEG forward solution in rabbits

Zuerst erschienen in: Biomedical Engineering = Biomedizinische Technik. - Berlin [u.a.] : de Gruyter. - 57 (2012), Suppl. 1, Track-M, p. 309.

Erstveröffentlichung: 2012-09-04

ISSN (online): $\quad$ 1862-278X

ISSN (print): 0013-5585

DOI: $\quad 10.1515 / \mathrm{bmt}-2012-4504$

[Zuletzt gesehen: 2019-08-15]

„Im Rahmen der hochschulweiten Open-Access-Strategie für die Zweitveröffentlichung identifiziert durch die Universitätsbibliothek IImenau. “

"Within the academic Open Access Strategy identified for deposition by Ilmenau University Library."

„Dieser Beitrag ist mit Zustimmung des Rechteinhabers aufgrund einer (DFGgeförderten) Allianz- bzw. Nationallizenz frei zugänglich."

"This publication is with permission of the rights owner freely accessible due to an Alliance licence and a national licence (funded by the DFG, German

DFG

Research Foundation) respectively." 


\title{
Influence of finite element discretization on the EEG/MEG forward solution in rabbits
}

\author{
H. Sonntag ${ }^{1}$, J. Haueisen ${ }^{1}$, S. Lau ${ }^{1,2}$, R. Eichardt ${ }^{1}$, C. Wolters ${ }^{3}$, J. Vorwerk ${ }^{3}$, L. Grasedyck ${ }^{4}$, D. Güllmar ${ }^{5}$ \\ ${ }^{1}$ Institute of Biomedical Engineering and Informatics, Ilmenau University of Technology, Ilmenau, Germany; Her- \\ mann.Sonntag@tu-ilmenau.de \\ ${ }^{2}$ NeuroEngineering Laboratory, Department of Electrical \& Electronic Engineering, University of Melbourne, Austral- \\ ia; Stephan.Lau@tu-ilmenau.de \\ ${ }^{3}$ Institute for Biomagnetism and Biosignalanalysis, University of Muenster, 48149, Muenster, Germany; car- \\ sten.wolters@uni-muenster.de \\ ${ }^{4}$ Institut für Geometrie und Praktische Mathematik, RWTH Aachen, Germany; lgr@igpm.rwth-aachen.de \\ ${ }^{5}$ Medical Physics Group, Department of Diagnostic and Interventional Radiology, Jena University Hospital, Germany; \\ Daniel.Guellmar@med.uni-jena.de
}

\section{Introduction}

Magnetoencephalography (MEG) and electroencephalography (EEG) are non-invasive methods to assess neuronal activity in the brain by means of source reconstruction. Modelling of the field distribution is often performed with the finite element (FE) method. Here we address the influence of the FE discretization on the accuracy of the forward solution.

\section{Methods}

A total of 55 hexahedral FE models with side lengths of 0.25 to $1 \mathrm{~mm}$ of a rabbit's head were constructed from an MRI data set (conductivities: $0.33 \mathrm{~S} / \mathrm{m}$ skin, $0.0042 \mathrm{~S} / \mathrm{m}$ skull, $1.79 \mathrm{~S} / \mathrm{m}$ cerebrospinal fluid, $0.337 \mathrm{~S} / \mathrm{m}$ grey matter, $0.14 \mathrm{~S} / \mathrm{m}$ white matter). EEG was simulated at 1330 electrode positions around the head and MEG was simulated at 3x144 magnetometer positions above the head. Dipolar sources were placed in one hemisphere of the cortex (365 positions with 3 orientations each). Two different methods for modelling the dipolar sources were used: the Saint-Venant approach and the full subtraction method. The simulation results of the model with the finest FE resolution served as reference and all other simulated field and potential distributions were compared by means of the relative magnitude error (MAGrel) and relative difference measure $(\mathrm{RDM})$.

\section{Results}

For our models, the Saint-Venant approach and the full subtraction method yielded similar results. The model resolutions could be subdivided into 2 groups. Up to about $0.5 \mathrm{~mm}$ element size in a 2-compartment brain model and $0.75 \mathrm{~mm}$ in a 5-compartment head model, the errors (i.e., model and numerical errors) in both RDM and MAGrel were similar to the model errors in spherical volume conductors. Beyond these resolutions we observed increases in both RDM and MAGrel.

\section{Conclusion}

We concluded that a FE size of less than $0.5 \mathrm{~mm}$ should be used to solve the forward problem in source reconstruction schemes in rabbits. In the human head somewhat larger sizes might be applicable. 